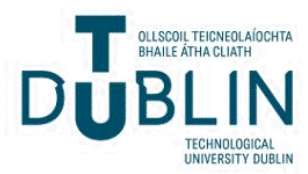

Technological University Dublin

ARROW@TU Dublin

\section{Optimisation of Fucoxanthin Extraction From Irish Seaweeds by Response Surface Methodology}

\author{
Emer Shannon \\ Technological University Dublin, emer.shannon@tudublin.ie \\ Nissreen Abu-Ghannam \\ Technological University Dublin, nissreen.abughannam@tudublin.ie
}

Follow this and additional works at: https://arrow.tudublin.ie/schfsehart

Part of the Food Chemistry Commons, and the Human and Clinical Nutrition Commons

\section{Recommended Citation}

Shannon, E. and Abu-ghannam, N. (2016) Optimisation of fucoxanthin extraction from Irish seaweeds by response surface methodology. Journal of Applied Phycology, Nov. 2016. doi:10.1007/

s10811-016-0983-4

This Article is brought to you for free and open access by the School of Food Science and Environmental Health at ARROW@TU Dublin. It has been accepted for inclusion in Articles by an authorized administrator of ARROW@TU Dublin. For more information, please contact arrow.admin@tudublin.ie, aisling.coyne@tudublin.ie, gerard.connolly@tudublin.ie.






\title{
Optimisation of fucoxanthin extraction from Irish seaweeds by response surface methodology
}

\author{
Emer Shannon $^{1}$ • Nissreen Abu-Ghannam ${ }^{1}$
}

Received: 21 June 2016 / Revised and accepted: 11 October 2016

(C) Springer Science+Business Media Dordrecht 2016

\begin{abstract}
Fucoxanthin is a xanthophyll pigment which occurs in marine brown algae (Phaeophyceae). The anti-diabetic, anti-obesity, anti-cancer, and antioxidant properties of fucoxanthin have been widely reported. Macroalgae, particularly brown seaweeds, grow prolifically around Irish coasts, representing a valuable resource of nutraceuticals such as fucoxanthin for functional food applications. The aim of this study was to maximise the solvent extraction yield from three anatomically discrete regions of the seaweed thallus: blade, stipe, and holdfast. Response surface methodology was applied to determine optimum parameters for extraction of fucoxanthin from the seaweed, Fucus vesiculosus, as a model species. A central composite design was applied with four extraction variables: time $(30-70 \mathrm{~min})$, temperature $\left(30-70^{\circ} \mathrm{C}\right)$, solvent $\mathrm{pH}(5.0-9.0)$, and percentage acetone $(30-70 \%)$. Fucoxanthin content of extracts was quantified by highperformance liquid chromatography. Percentage acetone was found to have the most significant $(P=0.0002)$ effect on fucoxanthin yield, followed by $\mathrm{pH}(P=0.028)$ and temperature $(P=0.049)$. Multiple response optimisation determined that fucoxanthin yield from $F$. vesiculosus may be maximised by incubating at $30.0{ }^{\circ} \mathrm{C}$ for $36.5 \mathrm{~min}, \mathrm{pH} 5.7$, with $62.2 \%$ acetone. Optimised responses were applied to a further nine brown seaweeds; Alaria esculenta, Ascophyllum nodosum,
\end{abstract}

Nissreen Abu-Ghannam

nissreen.abughannam@dit.ie

Emer Shannon

emer.shannon@dit.ie

1 Dublin Institute of Technology, School of Food Science and Environmental Health, College of Sciences and Health, Cathal Brugha Street, Dublin D01 HV58, Republic of Ireland
Fucus serratus, Himanthalia elongata, Laminaria digitata, Laminaria hyperborea, Pelvetia canaliculata, Saccharina latissima, and Saccorhiza polyschides. In all species, the blades contained significantly more fucoxanthin than stipes, while holdfasts contained the least. Alaria esculenta blade had the greatest yield $\left(0.870 \mathrm{mg} \mathrm{g}^{-1}\right.$ dry mass), followed by F. vesiculosus blade $\left(0.699 \mathrm{mg} \mathrm{g}^{-1}\right)$ and $L$. digitata blade $\left(0.650 \mathrm{mg} \mathrm{g}^{-1}\right)$.

Keywords Fucoxanthin · Nutraceutical $\cdot$ Irish brown seaweeds - Yield optimisation by response surface methodology $\cdot$ High-value algal bioactives $\cdot$ Antioxidant

\section{Introduction}

Fucoxanthin is a light-harvesting carotenoid that occurs in the chloroplasts of the eukaryotic Chromalveolata (Phylum Ochrophyta), including brown macroalgae, or seaweeds, (Phaeophyceae), and microalgal diatoms (Bacillariophyceae) (Cavalier-Smith and Chao 2006). Fucoxanthin is estimated to account for more than $10 \%$ of the total production of carotenoids in nature, and is responsible for the brown to yellow colour of brown macroalgae (seaweeds) and brown microalgae (diatoms) (Hurd et al. 2014). Fucoxanthin was first isolated in Germany in 1914 from Dictyota, Fucus, and Laminaria (Willstätter and Page 1914). Industrially, Japanese Wakame (Undaria pinnatifida) is the most widely utilised seaweed for fucoxanthin extraction due to high concentrations of the pigment in the lipid extract (up to $9.6 \%$ of total lipids) (Maeda et al. 2005). Irish coastlines support the growth of brown seaweeds. The total average annual value of seaweed production in Ireland has been estimated at $€ 23$ million. Approximately $36,000 \mathrm{t}$ of seaweed is harvested in Ireland each year, the majority of which is from brown 
species, which is used primarily as fertiliser or incorporated into livestock feed. Only $1 \%$ is processed into higher value nutraceuticals, cosmetics, and foods. However, this small percentage accounts for $\sim 30 \%$ of the total commercial value (Stengel and Dring 1998; Walsh and Watson 2011; Dring et al. 2013; Walsh 2016). The economic justification for this study is the high commercial value of fucoxanthin. In 2015, world fucoxanthin production reached approximately $500 \mathrm{t}$, with an expected increase of at least $5.3 \%$ per annum between 2016 and 2021 (Joel 2016). The global market for total carotenoids rose in value from US $\$ 1.20$ billion in 2010 to 1.5 billion in 2014. Although some of these carotenoids are synthetically derived, a substantial section of this market constitutes naturally produced compounds such as $\beta$-carotene and astaxanthin a xanthophyll chemically similar to fucoxanthin (Borowitzka 2013; Ulrich 2015). As a functional food, fucoxanthin has already been incorporated as an ingredient in products such as pasta, biscuits, and dips by a number of food companies worldwide (Prabhasankar et al. 2009; Oryza 2011). Fucoxanthin supplements are generally recognised as safe by the European Food Safety Authority, Japan's Food for Specified Health Uses, and the US Food and Drug Administration. The broad health applications of fucoxanthin have only emerged in recent years. It has remained underutilised in food and pharmaceutical applications possibly due to its oxidative instability and the prohibitive costs of inefficient extraction methods. A leaner, efficient extraction methodology has the potential to increase product yield.

Fucoxanthin has been studied clinically for its efficacy against many diseases. It has been shown in vivo to have activity against cancer (Nakazawa et al. 2009; Jaswir et al. 2013), type II diabetes (Oh et al. 2016), obesity (Maeda et al. 2007), cholesterol (Beppu et al. 2012), inflammatory disorders (Shiratori et al. 2005), tumour angiogenesis (Martin 2015), malaria (Briglia et al. 2015), hypertension (Sivagnanam et al. 2015), and as a $\beta$-secretase 1 inhibitor in Alzheimer's disease (Jung et al. 2016). Epidemiological data has suggested that the regular consumption of seaweeds can reduce the risk of developing diseases associated with oxidative stress. As a dietary antioxidant, fucoxanthin improves the antioxidant capacity of blood serum levels (Kang et al. 2014), and is capable of quenching reactive oxygen species under hypoxic physiological conditions, unlike the majority of food-derived antioxidants (Kaneko et al. 2013). Reactive oxygen species are known to cause cellular damage, which is implicated in the pathogenesis of disorders such as cardiovascular disease, cancer, metabolic syndrome, and type II diabetes. A study by Zaragozá et al. (2008) on the antioxidant effect of an extract of Fucus vesiculosus containing $0.0012 \%$ fucoxanthin, found that antioxidant activity increased in ex vivo assays of erythrocytes and plasma, after 4 weeks of daily oral administration in rats. Significant antioxidant activity was also observed in non-cellular systems and in activated
RAW 264.7 mouse leukaemic monocyte macrophage cell lines. Fucoxanthin's anti-diabetic activity has been studied in mice with induced type II diabetes. It has been shown to improve insulin resistance and decrease blood glucose levels via regulation of cytokine secretions from white adipose tissue, and by promoting the recovery of blood glucose uptake to muscle by the up-regulation of GLUT4 mRNA expression. Fucoxanthin has also been shown to affect the peroxisome proliferator-activated receptor $\gamma(\operatorname{PPAR} \gamma)$ and promote gene expression related to lipid metabolism in adipocytes. In cultivated cells, fucoxanthin prevented inflammation and insulin resistance by inhibiting nitric oxide and PGE2 production through the down-regulation of iNOS and COX-2 mRNA expression; as well as adipocytokine production in white adipose tissue (Maeda et al. 2007; Mikami and Hosokawa 2013). A number of human clinical trials with fucoxanthin have been reported. For example, in Japan, a Kombu (Saccharina japonica) extract of $3 \%$ fucoxanthin was evaluated for its anti-metabolic syndrome activity in a human clinical trial. A daily dosage of the extract, equivalent to $0.5-$ $1.0 \mathrm{mg}$ pure fucoxanthin day ${ }^{-1}$, was found to have a significant effect on blood serum parameters related to metabolic syndrome (Oryza 2011). Abidov et al. (2010) conducted a double-blind placebo-controlled study at the Russian Academy of Medical Sciences of 115 non-diabetic, obese, premenopausal women with a liver fat content above $11 \%$. A daily supplement of $300 \mathrm{mg}$ brown seaweed extract containing $2.4 \mathrm{mg}$ fucoxanthin, combined with $300 \mathrm{mg}$ pomegranate seed oil was administered. An olive oil capsule was administered to the placebo group. The treatment group showed a significant increase in resting energy expenditure and mean weight loss of $4.9 \mathrm{~kg}$ after 16 weeks. No toxicity of fucoxanthin extracts has been reported to date, making it an excellent candidate for nutraceutical applications (Maeda et al. 2007; Zaragozá et al. 2008) (Fig. 1).

Fucoxanthin is a xanthophyll and shares some chemical and physical properties with carotenes, such as lipophilicity and antioxidant activity due to their ability to quench reactive oxygen and nitrogen species. However, the presence of oxygen in the hydroxyl and epoxide groups of xanthophylls makes them more polar than carotenes (Landrum 2009). Fucoxanthin can exist in a trans or cis configuration. The trans isomer is the more chemically stable and potent antioxidant of the two, and comprises $\sim 90 \%$ of the fucoxanthin found in nature (Nakazawa et al. 2009). In industry, fucoxanthin is most commonly extracted with solvents such as hexane, methanol, DMSO, ethanol, petroleum ether, diethyl ether, dimethyl ether, acetone, or ethyl acetate, and dried to a powder (Kanda et al. 2014). In algal cells, fucoxanthin is contained in the chloroplasts, within membrane-bound compartments called thylakoids. Fucoxanthin is produced most significantly in the blade of seaweeds, where the majority of photosynthesis occurs due to maximum light exposure at the ocean surface. 
(Lobban and Harrison 1994; Kita et al. 2015; Schmid and Stengel 2015). Intra-species fucoxanthin content varies widely. For example, Roh et al. (2008) reported Undaria pinnatifida (lyophilised stipe and blade combined) to contain $0.00048 \mathrm{\mu g} \mathrm{g}^{-1}$ (dm) (dry mass) fucoxanthin, while Fung et al. (2013) found $4.96 \mathrm{mg} \mathrm{g}^{-1}$ (dm) (lyophilised blade) in the same species. Both intra, and inter, species differences such as this can be attributed to seasonal variations, geographic location, nutrient availability, exposure to sunlight, ontogenetic effects, and extraction methods, (Fung et al. 2013; Gosch et al. 2015; Terasaki et al. 2016).

The aim of this study was to maximise the organic solvent solid-liquid extraction of fucoxanthin from seaweed, using $F$. vesiculosus as a model species, quantify by HPLC, and to apply optimised responses to the holdfast, stipe, and blade of a further nine Irish brown seaweeds.

\section{Materials and methods}

\section{Chemicals}

Fucoxanthin standard (all-trans-fucoxanthin), acetone, hydrochloric acid, ethanol, and methanol were from Sigma-Aldrich (Rep. of Ireland). Ammonium acetate was from $\mathrm{BDH}$ Laboratory Supplies (Poole, UK).

\section{Samples}

Ten species of Irish brown seaweeds were selected for the study, based upon previously reported fucoxanthin content and commercial availability. Seaweeds were harvested and delivered fresh and whole within $24 \mathrm{~h}$, kept at a constant storage temperature of $4{ }^{\circ} \mathrm{C}$, in darkness. Fucus vesiculosus, Alaria esculenta, Ascophyllum nodosum, Fucus serratus, Himanthalia elongata, Laminaria digitata, Laminaria hyperborea, Pelvetia canaliculata, Saccharina latissima, and Saccorhiza polyschides were purchased from Quality Sea Vegetables, Burton Port, Co. Donegal, Rep. of Ireland. Authentication of species was provided by the supplier. Samples were harvested at low tide, in the intertidal area, between the high and low water marks, from the north-western coast of Ireland $\left(54.9823^{\circ} \mathrm{N}, 8.4343^{\circ} \mathrm{W}\right)$ in mid July 2015 at mean monthly air and seawater temperatures of $14.5^{\circ} \mathrm{C}$.

\section{Initial solvent trials and RSM range determination for $F$. vesiculosus extraction}

Initial trials with ethanol, methanol, DMSO, acetone, hexane, and ethyl acetate determined acetone to have the greatest extraction efficiency for the model species, $F$. vesiculosus holdfast, stipe, and blade. Pre-RSM extraction trials for incubation time, temperature, solvent $\mathrm{pH}$, and percentage acetone were carried out in the following ranges: $30 \mathrm{~min}-10 \mathrm{~h}$ (increments of $30 \mathrm{~min}$ ), $20-100^{\circ} \mathrm{C}$ (increments of $10^{\circ} \mathrm{C}$ ), solvent $\mathrm{pH} 5.0$ 9.0 (increments of 1.0), and $0-100 \%$ acetone (increments of $10 \%)$. pH was adjusted with $\mathrm{HCl}(0.01 \mathrm{M})$, based upon previously published extraction protocols. Quantification of fucoxanthin by HPLC determined that there was no statistically significant $(P \geq 0.05)$ increase in $F$. vesiculosus fucoxanthin content below or above the following ranges: time (30$70 \mathrm{~min})$, temperature $\left(30-70^{\circ} \mathrm{C}\right)$, solvent $\mathrm{pH}(5.0-9.0)$, and acetone (30-70\%). Accordingly then, these ranges were used as the upper and lower limits for the RSM design of experiment.

\section{Response surface methodology design}

Response surface methodology was selected as the statistical method as it has been successfully applied in this laboratory for the optimisation of bioactive extraction from a variety of seaweed types. To investigate the effect of factors (incubation time, temperature, $\mathrm{pH}$, and percentage acetone) on the extraction efficiency of fucoxanthin from $F$. vesiculosus (blade), a $2^{4}$ + star central composite design was applied using Statgraphics Centurion XV (StatPoint Technologies Inc., USA). The following equation (Eq. 1) was used to calculate the total number of designed experiments where $k$ is the number of independent variables.

$N=2^{k}+2 k=n_{0}$

Variance analysis was conducted and the following binary quadratic equation (Eq. 2) was constructed where $y$ is the predicted response, $B_{0}$ is the intercept term, $B_{i}$ is the linear coefficient, $B_{i j}$ are the quadratic coefficients, and $X_{i}$ and $X_{j}$ are the levels of the independent variables:

$y=B_{0}+\sum_{i=1}^{3} B_{i} X_{i}+\sum_{i=1}^{3} B_{i i} X_{i}^{2}+\sum_{i-1}^{3} \sum_{j=i+1}^{3} B_{i j} X_{i j}$
Fig. 1 Molecular structure of fucoxanthin<smiles>CC(=O)O[C@@H]1CC(C)(C)C(=C=CC(C)=CC=CC(C)=CC=CC=C(C)C=CC=C(C)C(=O)CC23O[C@]2(C)C[C@@H](O)CC3(C)C)[C@](C)(O)C1</smiles> 
Four variables were used in this study, therefore values of $i$ and $j$ ranged from 1 to 4 . Using a $2^{4}+$ star central composite design with four independent variables, 28 variable combinations in experimental runs were generated by the design. The effects of unexpected variability in the observed responses was minimised by randomisation.

Experimental data generated from the central composite design were fitted to a second-order polynomial regression model (Eq. 3) where $Y$ is the predicted response (here, fucoxanthin), and $X_{1}$ (temperature), $X_{2}$ (time), $X_{3}$ (solvent $\mathrm{pH}$ ), and $X_{4}$ (\% acetone) are the coded values of the independent variables.

$$
\begin{aligned}
Y= & B_{0}+\left(B_{1} X_{1}\right)+\left(B_{2} X_{2}\right)+\left(B_{3} X_{3}\right)+\left(B_{4} X_{4}\right) \\
& +\left(B_{12} X_{1}^{2}\right)+\left(B_{13} X_{1} X_{2}\right)+\left(B_{14} X_{1} X_{3}\right) \\
& +\left(B_{23} X_{1} X_{4}\right)+\left(B_{24} X_{2}^{2}\right)+\left(B_{34} X_{3} X_{4}\right) \\
& +\left(B_{11} X_{2} X_{4}\right)+\left(B_{22} X_{3}^{2}\right)+\left(B_{33} X_{3} X_{4}\right)+\left(B_{44} X_{4}{ }^{2}\right)
\end{aligned}
$$

RSM statistical analysis Statistical interpretation of experimental data generated by the model was evaluated by analysis of variance (ANOVA) and coefficient of determination, $R^{2}$, which measures goodness of fit of the regression model. Regression analysis and response surface plotting was performed to establish optimum parameters for the extraction of fucoxanthin. For each independent variable, quadratic models were represented as response surface optimisation plots. Significance of the model and data was determined at the $95.0 \%$ confidence level $(\alpha=0.05)$.

\section{Sample preparation}

Immediately upon delivery, fresh, raw seaweeds were placed in a colander and thoroughly rinsed with cold running tap water (Dublin city mains) to remove epiphytes and debris. With a clean knife, each thallus was divided into its three morphologically discrete sections; holdfast, stipe, and blade; and chopped into $2 \mathrm{~cm}$ pieces. Samples were frozen to $-80^{\circ} \mathrm{C}$. Aliquots of frozen samples $(\sim 10 \mathrm{~g})$ were crushed in a mortar and pestle with liquid nitrogen and stored at $-80{ }^{\circ} \mathrm{C}$ until extraction.

\section{Extraction procedure using RSM optimised parameters}

The extraction procedure was based upon protocols optimised in this laboratory for seaweed (Rajauria et al. 2013). Extraction parameters optimised by RSM for $F$. vesiculosus were used for all samples.

Raw seaweed and solvent were combined in a ratio of 1:10 $(w / v)$. Nitrogen crushed seaweed $(2 \mathrm{~g})$ was incubated in an orbital incubator shaker with acetone $(20 \mathrm{~mL}, 62.2 \%$, $\mathrm{pH}$ 5.7) in a flask covered with Parafilm for $36.5 \mathrm{~min}$ at $30{ }^{\circ} \mathrm{C}, 100 \mathrm{rpm}$, in the dark. The flask contents were transferred to Nalgene tubes and centrifuged (10 min, $\left.12,000 \times g 4^{\circ} \mathrm{C}\right)$. The supernatant was retained. The pellet was washed and centrifuged six times with acetone $(20 \mathrm{~mL}$, $62.2 \%, \mathrm{pH} 5.7$ ). The pooled supernatant was filtered (Grade 1 filter paper, $11 \mu \mathrm{m}$ pore, Whatman, UK) and reduced by evaporation (Laborota 4002 Heidolph rotary evaporator) at $30{ }^{\circ} \mathrm{C}$ to $5 \mathrm{~mL}$. Extracts were frozen at $-80^{\circ} \mathrm{C}$ for HPLC analysis.

\section{Quantification of fucoxanthin}

Preparation of seaweed extract stock solutions Frozen seaweed extracts were lyophilised to a powder $(0.02 \mathrm{mbar}$, $50{ }^{\circ} \mathrm{C}$, Labconco Freeze-Drier) for $24 \mathrm{~h}$. Stock solutions of seaweed extracts were prepared for HPLC analysis by dissolving lyophilised seaweed extract $(100 \mathrm{mg})$ in acetone $(10 \mathrm{~mL}, 62.2 \%)$. Samples were syringefiltered (Sigma-Aldrich Millex Durapore PVDF $0.22 \mu \mathrm{m}$ pore, $13 \mathrm{~mm}$ diam.) into HPLC vials (Waters $2 \mathrm{~mL}$ LCGC certified clear glass $12 \times 32 \mathrm{~mm}$ screw neck vial, with pre-slit PTFE/silicone septa cap).

HPLC-DAD analysis of fucoxanthin Chromatographic analysis of seaweed extracts was carried out according to a modified method developed by Billakanti et al. (2013). Fucoxanthin separation was achieved with HPLC (Alliance-Waters e2695 Separations Module, $400 \mathrm{~atm}$ pressure, at $4{ }^{\circ} \mathrm{C}$ ), equipped with a $\mathrm{C}_{18}$ reverse phase column (Waters XSelect, $4.6 \mathrm{~mm} \times 100 \mathrm{~mm}$, $3.5 \mu \mathrm{m}$ particle size), and a UV photodiode array detector (Waters 2998). Two mobile phases were determined to be optimal for HPLC-DAD analysis of the seaweed extracts. These were solvent A: $20 \mathrm{mM}$ sodium acetate; and solvent B: $100 \%$ methanol. Before use, $\mathrm{ddH}_{2} \mathrm{O}$ water was membrane filtered (Merck Millipore Simplicity 185). Mobile phases were filtered (Merck Millipore HVLP $0.45 \mu \mathrm{m}$ filter) and sonicated (Branson 5510 Ultrasonic Cleaner). Injection volume was $20 \mu \mathrm{L}$, with a constant flow rate of $0.15 \mathrm{~mL} \mathrm{~min}{ }^{-1}$. Detection was performed at $449 \mathrm{~nm}$. A 60-min gradient programme was used, at a constant temperature of $60{ }^{\circ} \mathrm{C}$. Analysis was carried out in triplicate.

HPLC-DAD data analysis Commercial fucoxanthin standard solutions were prepared in concentrations of 5,10 , 20, 30, 40, 50, and $100 \mu \mathrm{g} \mathrm{mL}^{-1}$ in ethanol. The area under the peak (AUP) of those corresponding with retention times for fucoxanthin standards was plotted against concentration $\left(\mu \mathrm{g} \mathrm{mL} \mathrm{m}^{-1}\right)$ to make a standard curve. The regression equation was obtained as $y=1,000,000 x+1,000,000$. The $R^{2}$ value was 0.999 . The concentration of fucoxanthin in the seaweed samples was extrapolated from the equation generated. 


\section{Statistical analysis}

All experiments were conducted in triplicate $(n=3)$ and replicated at least twice. Results are expressed as mean values \pm standard deviation. All statistical analyses and data were fitted to models using Statgraphics Centurion $X V$. The coefficient of determination $\left(R^{2}\right)$ and mean square error (MSE) were used as criteria for adequacy of fit. Multiple range tests were used to determine least significant differences between samples at the $95.0 \%$ confidence level $(\alpha=0.05)$.

\section{Results}

\section{RSM optimisation of acetone extraction of fucoxanthin from $F$. vesiculosus}

Using a $2^{4}+$ star central composite design with four independent variables, 28 experimental runs were generated, with variable combinations of temperature, time, solvent $\mathrm{pH}$, and percentage acetone. Estimation results for fucoxanthin are presented in Table 1, showing the observed, or actual value of fucoxanthin, the predicted value of fucoxanthin using the fitted model, and 95.0\% confidence limits (upper and lower) for the mean response. Experimental run no. 13 showed the highest extraction efficiency of $0.696 \pm 0.02 \mathrm{mg} \mathrm{g}^{-1}(\mathrm{dm})$ fucoxanthin. The parameters for this run were $40{ }^{\circ} \mathrm{C}, 40 \mathrm{~min}$, solvent $\mathrm{pH} 6.0$, and $60 \%$ acetone.

The regression equation fitted to the experimental data is shown in Eq. 4, where $Y$ is the predicted response (fucoxanthin), and $X_{1}$ (temperature), $X_{2}$ (time), $X_{3}$ (solvent $\mathrm{pH}$ ), and $X_{4}$ (\% acetone) are the coded values of the independent variables.

$$
\begin{aligned}
Y= & -2.15312-\left(0.0342417 * X_{1}\right)-\left(0.00264167 * X_{2}\right) \\
& +\left(0.6535 * X_{3}\right)+\left(0.05435 * X_{4}\right)-\left(0.000223333 * X_{1}^{2}\right) \\
& +\left(0.00044375 * X_{1} * X_{2}\right)+\left(0.0033875 * X_{1} * X_{3}\right) \\
& +\left(0.0000975 * X_{1} * X_{4}\right)-\left(0.000395833 * X_{2}^{2}\right) \\
& +\left(0.0015625 * X_{3} * X_{4}\right)+\left(0.00015 * X_{2} * X_{4}\right) \\
& -\left(0.0649583 * X_{3}^{2}\right)-\left(0.00115 * X_{3} * X_{4}\right) \\
& -\left(0.000452083 * X_{4}{ }^{2}\right)
\end{aligned}
$$

Analysis of variance partitioned the variability in fucoxanthin yield for each of the four independent variables. The statistical significance of each effect, and their interaction amongst each other, was determined by comparing the mean square against an estimate of the experimental error. Three effects, temperature, solvent $\mathrm{pH}$, and percentage acetone were found to be significant. Percentage acetone had the most significant effect on fucoxanthin yield with a $P$ value of 0.0002 , followed by solvent $\mathrm{pH}(P=0.0284)$, and temperature
$(P=0.0492)$. Incubation time $(P=0.5599)$ was not found to be significant at the $95.0 \%$ confidence level. The $R$-squared statistic indicated that the model as fitted explained $78.58 \%$ of the variability in fucoxanthin yield in F. vesiculosus. The standard error of the estimate showed the standard deviation of the residuals to be 0.13 , with the average value of the residuals expressed as a mean absolute error of 0.08 .

The combination of factor levels required to maximise fucoxanthin yield in $F$. vesiculosus blade were determined to be $30.00{ }^{\circ} \mathrm{C}, 36.51 \mathrm{~min}$, solvent $\mathrm{pH} 5.70$, and $62.15 \%$ acetone. An optimum value of $0.745 \mathrm{mg} \mathrm{g}^{-1}(\mathrm{dm})$ was predicted. The greatest observed value obtained was $0.696 \pm 0.02 \mathrm{mg} \mathrm{g}^{-1}$ $(\mathrm{dm})$ in experimental run no. 13. This equates to $93.30 \%$ of $0.746 \mathrm{mg} \mathrm{g}^{-1}$, which is in good agreement with the predicted optimum value.

\section{Mathematical modelling}

Response surface plots (Fig. 2) were constructed according to the modelled experimental data. In each case, the effects of two variables on fucoxanthin yield were depicted in three dimensional surface plots while the two other variables were kept constant at zero level.

\section{HPLC separation of fucoxanthin}

Separation of fucoxanthin was achieved at $449 \mathrm{~nm}$ with a $\mathrm{C}_{18}$ reverse phase column and a UV photodiode array detector. A 60 min gradient programme at a constant temperature of $60{ }^{\circ} \mathrm{C}$ was used with two mobile phases, (A) $20 \mathrm{mM}$ sodium acetate, and (B) $100 \%$ methanol. Figure 3 illustrates the separation of fucoxanthin in an overlay chromatogram at $39.89 \mathrm{~min}$ in (A) all-trans-fucoxanthin standard peak $\left(10 \mu \mathrm{g} \mathrm{mL}^{-1}\right)$; (B) F. vesiculosus blade; (C) two isomers of cis-fucoxanthin; and (D) an unidentified compound, possibly zeaxanthin.

As discussed in the Introduction, fucoxanthin can exist in a trans or cis configuration. Peak A in Fig. 3 corresponds with those of the all-trans-fucoxanthin standard. It was expected that approximately $10 \%$ of fucoxanthin extracts from each species would contain isomers of cis-fucoxanthin. These were detected at retention times of 44.5 and $45.5 \mathrm{~min}$ in all extracts. When compared to published chromatograms for similar studies, they are most probably the 13-cis and 13'-cis isomers of fucoxanthin, ascribed as $\mathrm{C}$ in Fig. 3 (Fung et al. 2013; Indrawati et al. 2015). Peak D in Fig. 3 was an unidentified compound detected at a retention time of $49.0 \mathrm{~min}$ in all seaweed extracts. It may be zeaxanthin; a xanthophyll that occurs in brown macroalgae with chemical properties similar to fucoxanthin. It is readily soluble in acetone, and absorbs light 
Table 1 RSM estimation results for fucoxanthin content in $F$. vesiculosus blade

\begin{tabular}{|c|c|c|c|c|c|}
\hline $\begin{array}{l}\text { RSM } \\
\text { experiment no. }\end{array}$ & $\begin{array}{l}\text { Observed experimental } \\
\text { value } \mathrm{mg} \mathrm{g}^{-1}(\mathrm{dm})\end{array}$ & $\begin{array}{l}\sigma( \pm) \mathrm{mg} \mathrm{g}^{-1} \\
(\mathrm{dm})\end{array}$ & $\begin{array}{l}\text { Fitted value } \\
\mathrm{mg} \mathrm{g}^{-1}(\mathrm{dm})\end{array}$ & $\begin{array}{l}\text { Lower } 95 \% \\
\text { CL }\end{array}$ & $\begin{array}{l}\text { Upper } 95 \% \\
\text { CL }\end{array}$ \\
\hline 1 & 0.052 & 0.00 & 0.136 & -0.081 & 0.352 \\
\hline 2 & 0.380 & 0.02 & 0.301 & 0.085 & 0.518 \\
\hline 3 & 0.131 & 0.01 & 0.304 & 0.087 & 0.520 \\
\hline 4 & 0.450 & 0.03 & 0.492 & 0.350 & 0.633 \\
\hline 5 & 0.090 & 0.01 & 0.105 & -0.111 & 0.321 \\
\hline 6 & 0.120 & 0.02 & 0.042 & -0.175 & 0.258 \\
\hline 7 & 0.079 & 0.01 & 0.140 & -0.076 & 0.356 \\
\hline 8 & 0.054 & 0.01 & 0.126 & -0.090 & 0.342 \\
\hline 9 & 0.067 & 0.00 & 0.224 & 0.008 & 0.440 \\
\hline 10 & 0.079 & 0.00 & 0.068 & -0.148 & 0.284 \\
\hline 11 & 0.402 & 0.01 & 0.422 & 0.206 & 0.638 \\
\hline 12 & 0.481 & 0.02 & 0.365 & 0.149 & 0.582 \\
\hline 13 & 0.696 & 0.02 & 0.675 & 0.459 & 0.891 \\
\hline 14 & 0.263 & 0.03 & 0.250 & 0.034 & 0.466 \\
\hline 15 & 0.507 & 0.01 & 0.553 & 0.337 & 0.769 \\
\hline 16 & 0.404 & 0.05 & 0.364 & 0.148 & 0.580 \\
\hline 17 & 0.586 & 0.03 & 0.518 & 0.302 & 0.735 \\
\hline 18 & 0.413 & 0.01 & 0.286 & 0.070 & 0.503 \\
\hline 19 & 0.263 & 0.00 & 0.362 & 0.145 & 0.578 \\
\hline 20 & 0.587 & 0.02 & 0.580 & 0.364 & 0.796 \\
\hline 21 & 0.445 & 0.01 & 0.432 & 0.216 & 0.648 \\
\hline 22 & 0.586 & 0.02 & 0.492 & 0.350 & 0.633 \\
\hline 23 & 0.589 & 0.01 & 0.492 & 0.350 & 0.633 \\
\hline 24 & 0.475 & 0.03 & 0.477 & 0.261 & 0.694 \\
\hline 25 & 0.254 & 0.01 & 0.100 & -0.116 & 0.316 \\
\hline 26 & 0.342 & 0.02 & 0.492 & 0.350 & 0.633 \\
\hline 27 & 0.470 & 0.02 & 0.421 & 0.205 & 0.637 \\
\hline 28 & 0.374 & 0.01 & 0.422 & 0.205 & 0.638 \\
\hline
\end{tabular}

at wavelengths in the same range as fucoxanthin. It has been reported to have a retention time greater than fucoxanthin, and therefore elute slightly later (Bidigare et al. 2005; Billakanti et al. 2013). Purification of Peak D in Fig. 3 for further identification was not carried out as part of the present study's objective.

The comparative fucoxanthin content of all ten seaweeds and the difference between blade, stipe, and holdfast within each species is presented in Fig. 4. A statistically significant inter-species difference was observed between the means of the ten species, as well as an intraspecies difference between blade, stipe, and holdfast.

Dry mass content ranged from the lowest, in Saccorhiza polyschides holdfast $\left(0.030 \pm 0.001 \mathrm{mg} \mathrm{g}^{-1}\right)$, to the greatest in Alaria esculenta blade $\left(0.870 \pm 0.030 \mathrm{mg} \mathrm{g}^{-1}\right)$. No fucoxanthin was detected in the holdfasts of L. digitata, A. nodosum,
L. hyperborea, F. serratus, or $P$. canaliculata. In all ten species, there was a greater fucoxanthin content in the blade compared to the stipe, and least in the holdfast.

\section{Discussion}

RSM optimisation Acetone was the most significant RSM extraction variable and has been widely reported in literature as an efficient solvent for fucoxanthin extraction. For example, Schmid and Stengel (2015) successfully extracted fucoxanthin from eight species of Irish brown seaweed using $90 \%$ acetone; and Sudhakar et al. (2013) extracted more fucoxanthin from Sargassum, Padina, and Turbinaria species with $90 \%$ acetone, compared to ethanol. In terms of environmental safety and impact, acetone is also listed as a 'preferred' 
Fig. 2 Multiple response surface optimisation plots for

F. vesiculosus blade showing the effects of a time ( $\mathrm{min}$ ) and acetone (\%); $\mathbf{b}$ time ( $\mathrm{min})$ and solvent $\mathrm{pH}$; $\mathbf{c}$ time (min) and temperature $\left({ }^{\circ} \mathrm{C}\right)$; $\mathbf{d}$ temperature $\left({ }^{\circ} \mathrm{C}\right)$ and solvent $\mathrm{pH} ; \mathbf{e}$ temperature $\left({ }^{\circ} \mathrm{C}\right)$ and acetone $(\%)$; and $\mathbf{f}$ solvent $\mathrm{pH}$ and acetone (\%) on fucoxanthin yield
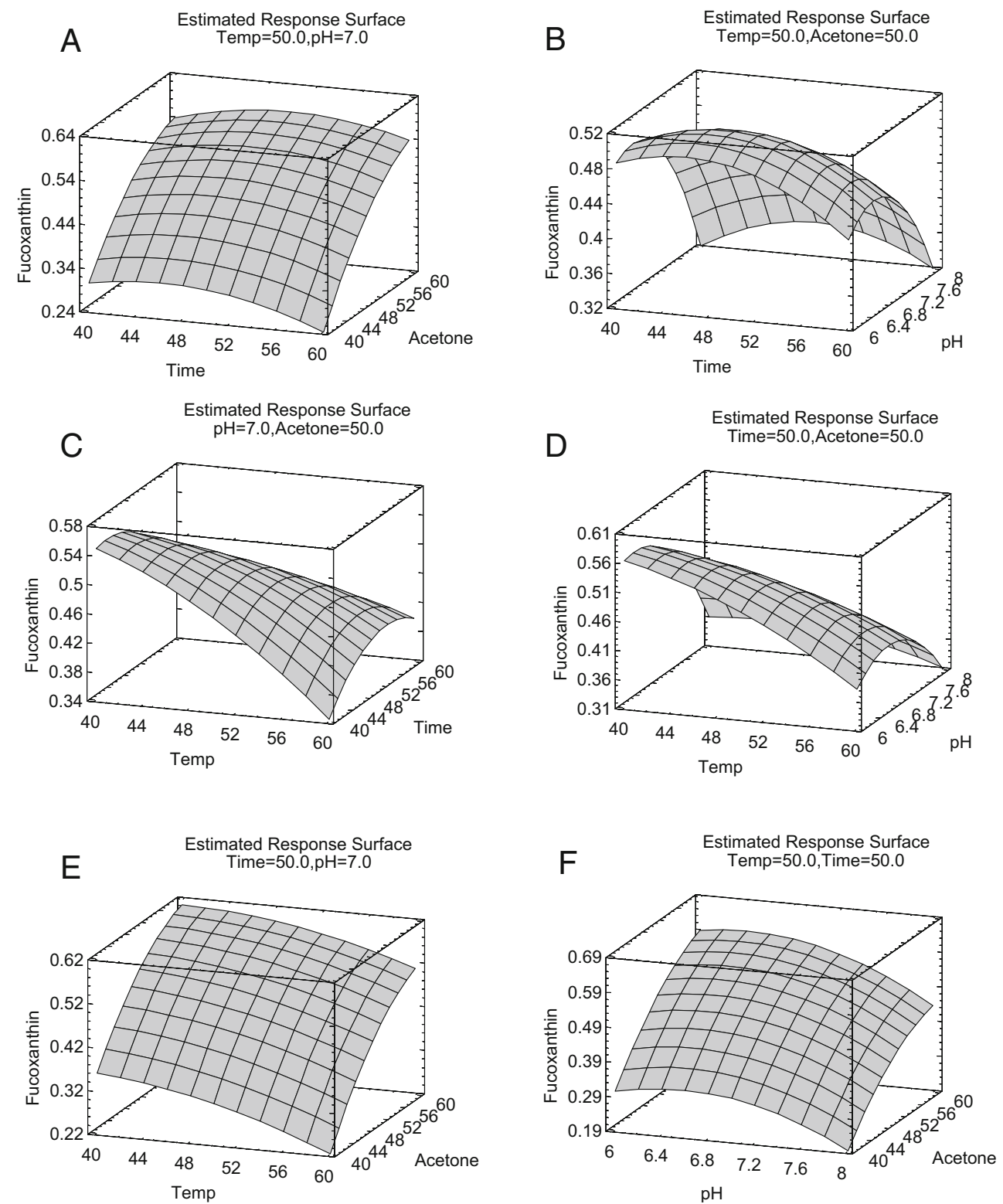

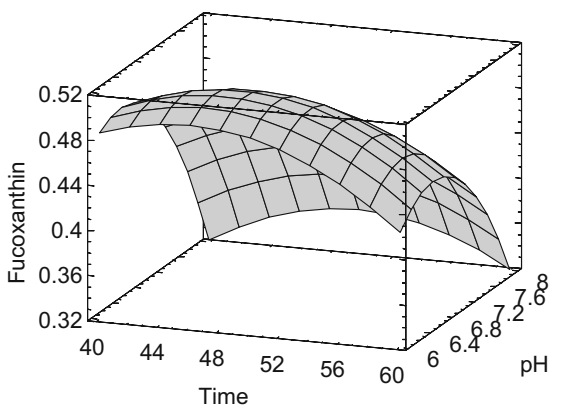

solvent in the American Chemical Society's Medicinal Chemistry Solvent Selection Guide (Hargreaves and Manley 2008).

Pigment extraction from macroalgae, particularly the larger kelps and wracks used in the present study, can be challenging due to the tough, polysaccharide-rich nature of the thalli. This may be overcome by maceration with liquid nitrogen. Crushing small aliquots of frozen seaweed in a mortar and pestle with liquid nitrogen ruptures the cell walls of the chloroplasts, releasing pigment-protein complexes from the membrane-bound thylakoids within, exposing them to the acetone solution. In comparison to chlorophyll $a$ and $c$, the fucoxanthin pigment-protein complex is less strongly bound to the thylakoid membrane, as it is an accessory pigment synthesised in response to reduced light availability. The second most significant RSM extraction variable was $\mathrm{pH}$, followed by temperature. Time was not found to be significant. Broad ranges have been reported for all three of these parameters, using various protocols. Grosso et al. (2015) reviewed extraction methods ranging from $\mathrm{pH} 3.8$ to 8.5 ; Bidigare et al. (2005) reported using $0{ }^{\circ} \mathrm{C}$ for up to $24 \mathrm{~h}$, Billakanti et al. (2013) $37^{\circ} \mathrm{C}$ for $2 \mathrm{~h}$ at pH 6.2, Quitain et al. (2013) $40{ }^{\circ} \mathrm{C}$ for $3 \mathrm{~h}$, Sivagnanam et al. (2015) $45{ }^{\circ} \mathrm{C}$ for $2 \mathrm{~h}$, Roh et al. (2008) $49.85{ }^{\circ} \mathrm{C}$ for $50 \mathrm{~min}$, and Shang et al. (2011) 40 

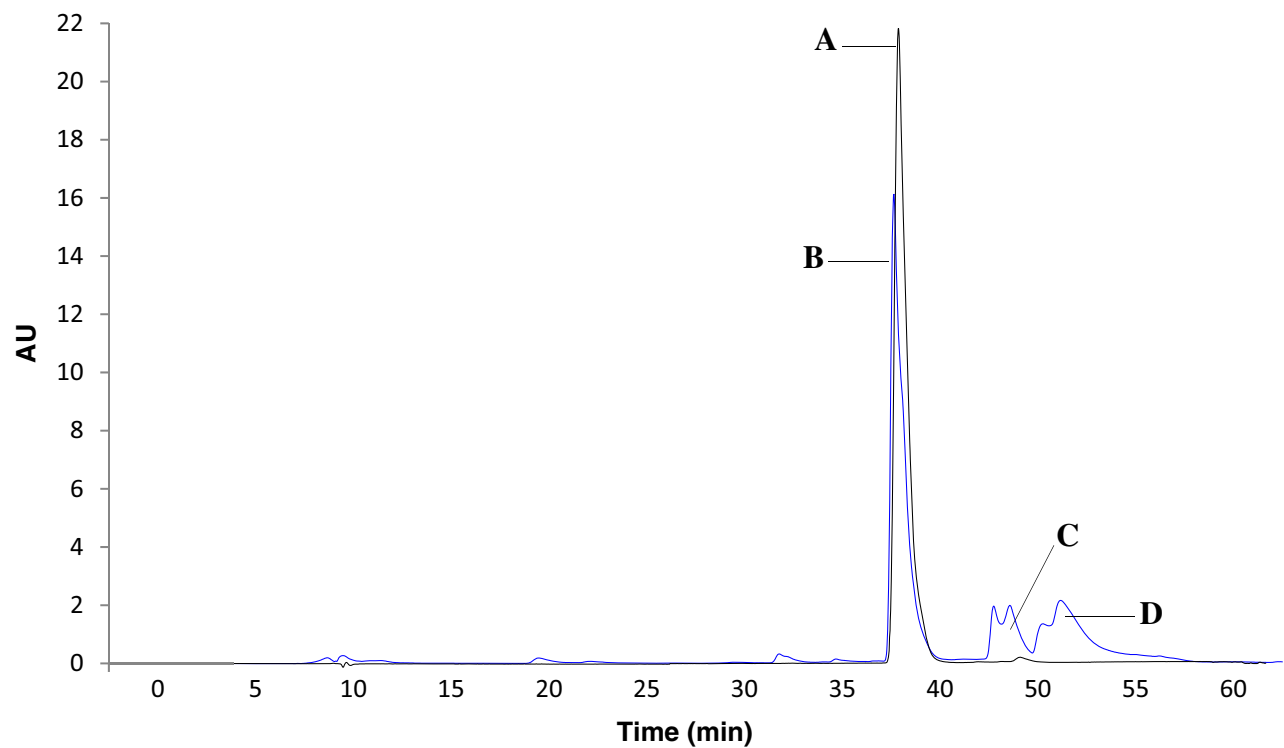

Fig. 3 HPLC separation of fucoxanthin in an overlay chromatogram at $39.89 \mathrm{~min}$ in a all-trans-fucoxanthin standard peak $\left(10 \mu \mathrm{g} \mathrm{mL}^{-1}\right)$; b F. vesiculosus blade; $\mathbf{c}$ two isomers of cis-fucoxanthin; and $\mathbf{d}$ an unidentified compound, possibly zeaxanthin

$100{ }^{\circ} \mathrm{C}$ for $5-15 \mathrm{~min}$. Since different algal species, solvents, and extraction methods require different temperatures, $\mathrm{pH}$ levels, and incubation times, the optimum parameters calculated in the present study may not be directly comparable to all previously reported methods.
Comparative fucoxanthin content The fucoxanthin results for the ten Irish seaweeds are in line with published values for fucoxanthin content in brown seaweeds from northern European temperate waters. Intra-thallus variations in algal pigment content can be attributed to a greater occurrence of

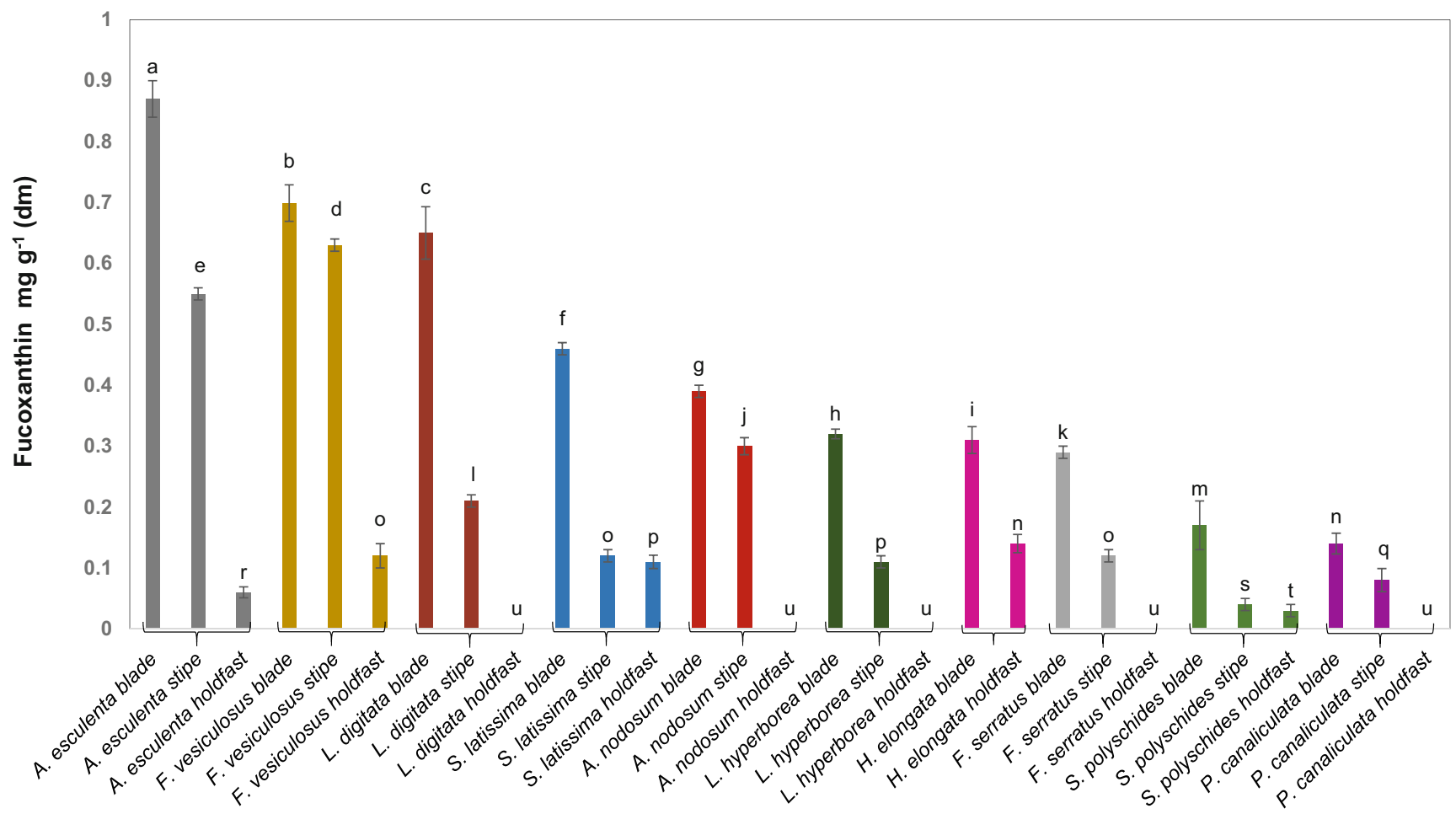

Species and thallus region

Fig. 4 Comparative fucoxanthin content ( $\mathrm{mg} \mathrm{g}^{-1}$ dry mass) per species and thallus region of ten Irish brown seaweeds. Values are the mean of three replicates \pm standard deviation. Letters denote least significant difference between columns $(P \leq 0.05)$ 
pigment-containing thylakoids in the blades, which function as the photosynthesis engines of macroalgae, compared to the stipe or holdfasts which have structural functions. Photoprotection of thallus regions near the ocean surface against ultraviolet light is another function of fucoxanthin in the blades, where it exerts its powerful antioxidant effect (Lobban and Harrison 1994; Stengel and Dring 1998; Hurd et al. 2014). The majority of observed results were in good agreement with published values for each species. For example, Schmid and Stengel (2015) conducted a study of fucoxanthin, in eight species of Irish brown macroalgae from the west coast of Ireland. Overall, the results of the present study were slightly higher. Schmid and Stengel (2015) reported harvesting of thalli in May 2013, $270 \mathrm{~km}$ south of the harvesting region used for the present study. The difference in geographic locations and seasonal variations may account for the difference in fucoxanthin contents, since thalli were harvested for the present study in July 2015. Pigment content variations in algae have been reported due to a number of influences such as seasonal variations, geographic location, sea temperature, nutrient availability, exposure to sunlight, and ontogenetic effects. For example, brown seaweeds harvested from September to March, during the mature phase of the sporophyte, commonly contain higher concentrations of fucoxanthin (Henley and Dunton 1995; Fung et al. 2013; Gosch et al. 2015; Terasaki et al. 2016). This has been attributed to the upregulation of the xanthophyll, or violaxanthin, cycle pathway in reduced levels of sunlight during the winter. Most other published values for fucoxanthin in brown macroalgae are within a range similar to the results of the present study. For example, Ramus et al. (1977) quantified fucoxanthin in the whole thallus of $F$. vesiculosus and A. nodosum harvested at Long Island Sound, USA. Fucus vesiculosus ranged from 0.202 to $0.751 \mathrm{mg} \mathrm{g}^{-1}$, and $A$. nodosum from 0.178 to $0.304 \mathrm{mg} \mathrm{g}^{-1}$.

Conclusion Fucoxanthin is a bioactive compound found in one of the most prolific and sustainable organisms on the planet, algae. Its efficacy and potential in terms of health applications have been widely reported. The results of this study show the significant distinction between blade, stipe, and holdfast in terms of fucoxanthin content. The findings are in good agreement with international published values for fucoxanthin content. In addition, RSM was shown to be an effective technique for optimising extraction conditions for maximum fucoxanthin yield. These findings may be applied in the development of lean extraction methodologies for value added seaweed products. The Irish government aims to position Ireland as 'The Green Food Island' and develop the annual value of Irish seaweed sector to $€ 30$ million by 2020 (Dring et al. 2013). The ten species under study grow prolifically, farmed and wild, around the Irish coast and can be harvested without damage to the base, allowing for continuous re- growth (Taelman et al. 2015). Irish brown seaweeds, particularly $A$. esculenta, $F$. vesiculosus, and $L$. digitata represent a potential source of fucoxanthin for nutraceutical applications.

Acknowledgments The authors wish to acknowledge funding from the Fiosraigh PhD Scholarship Programme, Dublin Institute of Technology.

\section{References}

Abidov M, Ramazanov Z, Seifulla R, Grachev S (2010) The effects of Xanthigen ${ }^{\mathrm{TM}}$ in the weight management of obese premenopausal women with non-alcoholic fatty liver disease and normal liver fat. Diabetes Obes Metab 12:72-81

Beppu F, Hosokawa M, Niwano Y, Miyashita K (2012) Effects of dietary fucoxanthin on cholesterol metabolism in diabetic/obese KK-A y mice. Lipids Health Dis 11:1-8

Bidigare RR, Van Heukelem L, Trees CC (2005) Analysis of algal pigments by high-performance liquid chromatography. In: Andersen RA (ed) Algal culturing techniques. Academic Press, NY, pp. 327-345

Billakanti JM, Catchpole OJ, Fenton TA, Mitchell KA, MacKenzie AD (2013) Enzyme-assisted extraction of fucoxanthin and lipids containing polyunsaturated fatty acids from Undaria pinnatifida using dimethyl ether and ethanol. Process Biochem 48:1999-2008

Borowitzka MA (2013) High-value products from microalgae - their development and commercialisation. J Appl Phycol 25:743-756

Briglia M, Calabró S, Signoretto E, Alzoubi K, Laufer S, Faggio C, Lang F (2015) Fucoxanthin induced suicidal death of human erythrocytes. Cell Physiol Biochem 37:2464-2475

Cavalier-Smith T, Chao EEY (2006) Phylogeny and megasystematics of phagotrophic heterokonts (kingdom Chromista). J Mol Evol 62: $388-420$

Dring M, Edwards M, Watson L (2013) Development and demonstration of viable hatchery and ongoing methodologies for seaweed species with identified commercial potential. Marine Institute Report no. 2009-3195, Dublin, Ireland

Fung A, Hamid N, Lu J (2013) Fucoxanthin content and antioxidant properties of Undaria pinnatifida. Food Chem 136:1055-1062

Gosch BJ, Paul NA, de Nys R, Magnusson M (2015) Seasonal and within-plant variation in fatty acid content and composition in the brown seaweed Spatoglossum macrodontum (Dictyotales, Phaeophyceae). J Appl Phycol 27:387-398

Grosso C, Valentao P, Ferreres F, Andrade PB (2015) Alternative and efficient extraction methods for marine-derived compounds. Mar Drugs 13:3182-3230

Hargreaves CR, Manley JB (2008) Collaboration to deliver a solvent selection guide for the pharmaceutical industry. ACS GCI, Pharmaceutical Roundtable. Philadelphia, pp 9-11

Henley WJ, Dunton KH (1995) A seasonal comparison of carbon, nitrogen, and pigment content in Laminaria solidungula and L. saccharina (Phaeophyta) in the Alaskan Arctic. J Phycol 31: 325-331

Hurd CL, Harrison PJ, Bischof K, Lobban CS (2014) Seaweed ecology and physiology. Cambridge University Press, Cambridge

Indrawati R, Sukowijoyo H, Wijayanti RDE, Limantara L (2015) Encapsulation of brown seaweed pigment by freeze drying: characterization and its stability during storage. Procedia Chem 14:353360

Jaswir I, Noviendri D, Salleh HM, Taher M, Miyashita K (2013) Isolation of fucoxanthin and fatty acids analysis of Padina australis and 
cytotoxic effect of fucoxanthin on human lung cancer (H1299) cell lines. Afr J Biotechnol 10:18855-18862

Joel J (2016) Global fucoxanthin market 2016 industry trends, sales, supply, demand. Analysis \& Forecast, New York

Jung HA, Ali MY, Choi RJ, Jeong HO, Chung HY, Choi JS (2016) Kinetics and molecular docking studies of fucosterol and fucoxanthin, BACE1 inhibitors from brown algae Undaria pinnatifida and Ecklonia stolonifera. Food Chem Toxicol doi: 10.1016/j. fct.2016.01.014

Kanda H, Kamo Y, Machmudah S, Goto M (2014) Extraction of fucoxanthin from raw macroalgae excluding drying and cell wall disruption by liquefied dimethyl ether. Mar Drugs 12:2383-2396

Kaneko M, Nagamine T, Nakazato K, Mori M (2013) The anti-apoptotic effect of fucoxanthin on carbon tetrachloride-induced hepatotoxicity. J Toxicol Sci 38:115-126

Kang M-C, Lee S-H, Lee W-W, Kang N, Kim E-A, Kim SY, Lee DH, Kim D, Jeon Y-J (2014) Protective effect of fucoxanthin isolated from Ishige okamurae against high-glucose induced oxidative stress in human umbilical vein endothelial cells and zebrafish model. J Funct Foods 11:304-312

Kita S, Fujii R, Cogdell RJ, Hashimoto H (2015) Characterization of fucoxanthin aggregates in mesopores of silica gel: electronic absorption and circular dichroism spectroscopies. J Photochem Photobiol A $313: 3-8$

Landrum JT (2009) Carotenoids: physical, chemical, and biological functions and properties. CRC Press, Boca Raton

Lobban CS, Harrison PJ (1994) Seaweed ecology and physiology. Cambridge University Press, Cambridge

Maeda H, Hosokawa M, Sashima T, Funayama K, Miyashita K (2005) Fucoxanthin from edible seaweed, Undaria pinnatifida, shows antiobesity effect through UCP1 expression in white adipose tissues. Biochem Biophys Res Commun 332:392-397

Maeda H, Hosokawa M, Sashima T, Miyashita K (2007) Dietary combination of fucoxanthin and fish oil attenuates the weight gain of white adipose tissue and decreases blood glucose in obese/diabetic KK-Ay mice. J Agric Food Chem 55:7701-7706

Martin LJ (2015) Fucoxanthin and its metabolite fucoxanthinol in cancer prevention and treatment. Mar Drugs 13:4784-4798

Mikami K, Hosokawa M (2013) Biosynthetic pathway and health benefits of fucoxanthin, an algae-specific xanthophyll in brown seaweeds. Int J Mol Sci 14:13763-13781

Nakazawa Y, Sashima T, Hosokawa M, Miyashita K (2009) Comparative evaluation of growth inhibitory effect of stereoisomers of fucoxanthin in human cancer cell lines. J Funct Foods 1:88-97

Oh J-H, Kim J, Lee Y (2016) Anti-inflammatory and anti-diabetic effects of brown seaweeds in high-fat diet-induced obese mice. Nutr Res Pract 10:42-48

Oryza (2011) Fucoxanthin: dietary ingredient for prevention of metabolic syndrome, antioxidation and cosmetics, <http://www.oryza.co. jp/pdf/english/Fucoxanthin_1.0.pdf > Oryza Oil \& Fat Chemical CO., LTD, Tokyo, Japan. Accessed 10 May 2016

Prabhasankar P, Ganesan P, Bhaskar N, Hirose A, Stephen N, Gowda LR, Hosokawa M, Miyashita K (2009) Edible Japanese seaweed, wakame (Undaria pinnatifida) as an ingredient in pasta: chemical, functional and structural evaluation. Food Chem 115:501-508

Quitain AT, Kai T, Sasaki M, Goto M (2013) Supercritical carbon dioxide extraction of fucoxanthin from Undaria pinnatifida. J Agric Food Chem 61:5792-5797
Rajauria G, Jaiswal AK, Abu-Ghannam N, Gupta S (2013) Antimicrobial, antioxidant and free radical-scavenging capacity of brown seaweed Himanthalia elongata from western coast of Ireland. J Food Biochem 37:322-335

Ramus J, Lemons F, Zimmerman C (1977) Adaptation of light-harvesting pigments to downwelling light and the consequent photosynthetic performance of the eulittoral rockweeds Ascophyllum nodosum and Fucus vesiculosus. Mar Biol 42:293-303

Roh M-K, Uddin MS, Chun B-S (2008) Extraction of fucoxanthin and polyphenol from Undaria pinnatifida using supercritical carbon dioxide with co-solvent. Biotechnol Bioprocess Eng 13:724-729

Schmid M, Stengel DB (2015) Intra-thallus differentiation of fatty acid and pigment profiles in some temperate Fucales and Laminariales. J Phycol 51:25-36

Shang YF, Kim SM, Lee WJ, Um B-H (2011) Pressurized liquid method for fucoxanthin extraction from Eisenia bicyclis (Kjellman) Setchell. J Biosci Bioeng 111:237-241

Shiratori K, Ohgami K, Ilieva I, Jin X-H, Koyama Y, Miyashita K, Yoshida K, Kase S, Ohno S (2005) Effects of fucoxanthin on lipopolysaccharide-induced inflammation in vitro and in vivo. Exp Eye Res 81:422-428

Sivagnanam SP, Yin S, Choi JH, Park YB, Woo HC, Chun BS (2015) Biological properties of fucoxanthin in oil recovered from two brown seaweeds using supercritical $\mathrm{CO}_{2}$ extraction. Mar Drugs 13:3422-3442

Stengel DB, Dring MJ (1998) Seasonal variation in the pigment content and photosynthesis of different thallus regions of Ascophyllum nodosum (Fucales, Phaeophyta) in relation to position in the canopy. Phycologia 37:259-268

Sudhakar MP, Ananthalakshmi JS, Nair BB (2013) Extraction, purification and study on antioxidant properties of fucoxanthin from brown seaweeds. J Chem Pharm Res 5:169-175

Taelman SE, Champenois J, Edwards MD, De Meester S, Dewulf J (2015) Comparative environmental life cycle assessment of two seaweed cultivation systems in North West Europe with a focus on quantifying sea surface occupation. Algal Res 11: 173-183

Terasaki M, Kawagoe C, Ito A, Kumon H, Narayan B, Hosokawa M, Miyashita K (2016) Spatial and seasonal variations in the biofunctional lipid substances (fucoxanthin and fucosterol) of the laboratory-grown edible Japanese seaweed (Sargassum horneri Turner) cultured in the open sea. Saudi J Biol Sci doi. doi:10.1016/j.sjbs.2016.01.009

Ulrich M (2015) The Global Market for Carotenoids - Report Code FOD025E. BCC Research. Online. <http://www.bccresearch. $\mathrm{com} / \mathrm{market}$-research/food-and-beverage/carotenoids-globalmarket-report-fod025e.html>. Accessed 20 Aug 2016.

Walsh M (2016) Seaweed Production in Ireland 2016. E-mail edn. Bord Iascaigh Mhara-Irish Sea Fisheries Board, Galway, Ireland

Walsh M, Watson L (2011) A market analysis towards the further development of seaweed aquaculture in Ireland. Bord Iascaigh MharaIrish Sea Fisheries Board, Galway, Ireland

Willstätter R, Page HJ (1914) Untersuchungen über Chlorophyll. XXIV Über die Pigmente der Braunalgen. Justus Liebigs Ann Chem 404: 237-271

Zaragozá MC, López D, Sáiz M, Poquet M, Pérez J, Puig-Parellada P, Marmol F, Simonetti P, Gardana C, Lerat Y (2008) Toxicity and antioxidant activity in vitro and in vivo of two Fucus vesiculosus extracts. J Agric Food Chem 56:7773-7780 